\title{
Reply: Intracranial aneurysm diameter and risk of rupture
}

\author{
Resposta: 0 diâmetro de aneurismas intracranianos e o risco de ruptura \\ Guilherme LEPSKI', Carlos A. F. LOBÃO', Stella TAYLOR', Paulo M. MESQUITA FILHO', Marcos TATAGIBA'
}

Dear Editor,

We are very satisfied with the discussion raised by our article entitled "Bleeding risk of small intracranial aneurysms in a population treated in a reference center" ${ }^{\prime \prime}$, and would like to thank Trivelato et al. $^{2}$ for their comments. Nevertheless, we noticed a misunderstanding that we would like to clarify. Our report did not intend to be a prospective epidemiological study about the risk of rupture of intracranial aneurysms. Plenty of studies have addressed this issue already, although the question still remains partially unanswered. Our study reports the scenario of a specific area in southern Germany (referred to in the local health system as "extended region of Stuttgart"), with a population of 3.5 million, and where the University Clinic of Tuebingen is a reference center in a network of many regional hospitals also involved in the treatment of ruptured aneurysms. As we pointed out in our paper, prevalence estimates of small aneurysms in the population is as high as $2-6 \%$. However, we must consider that these estimates are calculated based on samples, either samples from autopsy (and thus by definition, non-healthy subjects) or from diagnostic procedures in patients, which is also biased. It is speculated that series based on patients overestimate the prevalence of aneurysms, because children and young patients rarely undergo angiography. Beyond the discussion regarding the overestimation of aneurysm prevalence in the normal population, we must critique the risk estimates reported in large epidemiological series. Is it the case that small aneurysms are indeed very prevalent (yielding a small risk of bleeding), or are we overestimating their prevalence? Or alternatively, are the reported studies missing deaths caused by small aneurysm ruptures, for whatever reason (unreported deaths or deaths with unknown causes, etc.)? Some authors have even suggested that some series might be biased because the reference centers involved in the study selectively receive more complex cases (i.e., larger aneurysms). Another question we should ask is why Japanese and Finnish series report higher bleeding risks for small aneurysms. Are there in fact different biological factors in these populations? Or are we simply observing the effects of different health systems, which in these cases may just be more organized and less likely to lose cases in their study samples?

As mentioned in the discussion, $80 \%$ of the reported SAH in the United States were in aneurysms smaller than $10 \mathrm{~mm}$. Considering the drastic morbidity and high mortality in SAH, what would be the consequences for society if the medical community agreed on indiscriminate treatment of all intracranial aneurysms? Would the costs be justified?

We do not know the answers to all of these questions, and by reporting on a single center experience, the intent of our paper is to foster criticism and discussion, keeping readers' minds open to those questions and motivating the search for correct answers, rather than simplifying the question and automatically accepting the conclusions presented by large multicentric trials.

\section{References}

1. Lepski G, Lobão CA, Taylor S, Mesquita Filho PM, Tatagiba M. Bleeding risk of small intracranial aneurysms in a population treated in a reference center. Arq Neuropsiquiatr. 2019 May;77(5):300-9. https://doi.org/10.1590/0004-282X20190046
2. Trivelato FP, Ulhoa AC, Abud DG, Rezende MTS.

Intracranial aneurysm diameter and risk of rupture. Arq Neuropsiquiatr 2019;77(11):838. https://doi.org/10.1590/0004-282X20190146

'Universitätsklinik für Neurochirurgie, Eberhard Karls University, Tübingen, Deutschland.

Guilherme Lepski (iD https://orcid.org/0000-0002-9030-4192; Carlos Augusto Ferreira Lobão iD) https://orcid.org/0000-0001-7789-1663; Paulo M. Mesquita Filho (iD https://orcid.org/0000-0003-1375-9203; Stella Taylor (iD) https://orcid.org/0000-0001-7186-8868; Marcos Tatagiba (iD https://orcid.org/0000-0002-1627-9937

Correspondence:Carlos A. F. Lobão; Eberherd-Karls University - Neurosurgery Hoppe-Seyler-Str. 4 Tuebingen 72072, Germany; E-mail: caflobao@yahoo.com.br Conflict of interest: There is no conflict of interest to declare.

Received 24 October 2019; Accepted 31 October 2019 